consists of four sessions (two with the patient alone, one with the care giver alone, one together) that address potential barriers to discuss end of life issues (e.g. negative expectations concerning EoL issues and ACP) and two regular ACP sessions. Primary endpoint is the patient health-related QoL (FACIT-PAL). Secondary endpoints are general QoL; distress; acceptance; depressiveness; evaluation of the intervention; care-givers: heath-related and general QoL. Patients' QoL is evaluated every second month for one year. In the event of the patients death, care-givers are asked to answer questions about concordance of advance care planning with actual care and the patients quality of dying.

Results Until 11/18, 75 patients have been randomized, 13 patients finished the intervention, 21 patients died, denial rate is at approx. $55 \%$.

Conclusion This study tries to implement ACP in a palliative cancer setting in Germany. The efficacy and effectiveness of a novel collaborative ACP intervention are evaluated.

\section{P58 ADVANCE CARE PLANNING IN GLIOBLASTOMA PATIENTS: DEVELOPMENT OF A DISEASE-SPECIFIC ACP PROGRAM}

${ }^{1} \mathrm{~L}$ Fritz ${ }^{*},{ }^{1} \mathrm{H}$ Zwinkels, ${ }^{1,2} \mathrm{~J}$ Koekkoek, ${ }^{3,4}$ J Rejineveld, ${ }^{1} \mathrm{M}$ Vos, ${ }^{1,2} \mathrm{~L}$ Diven, ${ }^{5} \mathrm{R}$ Pasman, 1,2 $\mathrm{M}$ Taphoorn. ${ }^{1}$ Haaglanden Medical Center, The Hague, Netherlands; ${ }^{2}$ Leiden University Medical Center, Leiden, Netherlands; ${ }^{3}$ Amsterdam University Medical Centers (location VUmc), Amsterdam, Netherlands; ${ }^{4}$ Amsterdam University Medical Centers (location Academic Medical Center), Amsterdam, Netherlands; ${ }^{5}$ Amsterdam University Medical Centers, Vrije Universiteit Amsterdam, Amsterdam Public Health research institute, Expertise center for Palliative care Amsterdam, Amsterdam, Netherlands

\subsection{6/spcare-2019-ACPICONGRESSABS.141}

Background It is unknown if implementation of an Advance Care Planning (ACP) program is feasible in daily clinical practice for glioblastoma patients. We aimed to develop an ACP program, and assessed the preferred content, the best time to introduce such a program in the disease trajectory, and possible barriers and facilitators for participation and implementation.

Methods A focus group with health care professionals (HCPs) as well as individual semi-structured interviews with patients and proxies (of both living and deceased patients) were conducted.

Results All predefined topics were considered relevant by participants, including the current situation, worries and fears, (supportive) treatment options, and preferred place of care/ death. Although HCPs and proxies of deceased patients indicated that the program should be implemented relatively early in the disease trajectory, patient-proxy dyads were more ambiguous. Several patient-proxy dyads indicated that the program should be initiated later in the disease trajectory. If introduced early, topics about the end-of-life should be postponed. A frequently mentioned barrier for participation was that the program would be confronting, while a facilitator included access to information.

Conclusion This study resulted in an ACP program specifically for glioblastoma patients. Although participants agreed on the content of the program, the optimal timing of introducing such a program was a matter of debate. Our solution is to offer the program shortly after diagnosis, but let patients and proxies decide which topics they want to discuss. The impact of the program on several patient- and care-related outcomes will be evaluated in a next step.

\section{P59 CHANGES IN END-OF-LIFE DECISIONS BETWEEN PATIENTS WITH ADVANCED CANCER AND THEIR FAMILY MEMBERS AFTER IMPLEMENTATION OF THE NURSING PROGRAM}

M Watanabe*, M Masujima. Chiba University, CHIBA, Japan

\subsection{6/spcare-2019-ACPICONGRESSABS. 142}

Background Patients with advanced cancer and their family members tend not to adequately communicate with each other about the end of life in Japan. Previous studies have clarified that the obstacles for conversation are mostly posed by family members. Thus, the authors developed a nursing program for family members of patients with advanced cancer to promote End of Life Discussion (EOLD). This study aimed to clarify changes in EOLD between patients and their family members after implementation of the nursing program.

Methods The researchers performed three interview sessions, based on the manual for nursing practices and the guidebook for family members, which were established by the researchers. The interviews were recorded, and the data was analyzed qualitatively and inductively. This study was conducted with approval by the Ethical Review Board of the affiliated institution of the researcher.

Results The research participants were ten family members of patients with advanced cancer (seven females, forty to eightynine years of age). The twelve categories were extracted regarding changes in EOLD between patients and their family members, including the following: They realized the necessity to discuss the end of life. They were able to discuss subjects that they had been concerned about. They wrote down what they discussed. They were highly motivated to continue talking about the end of life.

Conclusion This research clarified that varied effects on the promotion of EOLD can be expected from this nursing program according to the situation and conversation of each patient and their family members.

\section{P61 THE EFFECT OF PRIORITISING TREATMENT GOALS ON DECISION SELF-EFFICACY AMONG OLDER PATIENTS WITH CANCER IN A PALLIATIVE SETTING (OPTION- STUDY)}

ME Stegmann*. Universitair Medisch Centrum Groningen, Groningen, Netherlands

\subsection{6/spcare-2019-ACPICONGRESSABS. 143}

Background In the Netherlands, the General Practitioner (GP) is generally not involved in treatment decisions in cancer. However, the GP often has a long history with patients and can help to explore patients' values, especially in older patients. This can help the patient prepare for shared decision making with the oncologist. The aim of this randomised controlled trial is to study the effect of a conversation about treatment goals between GPs and patients on self-efficacy just after the diagnosis of non-curable cancer.

Methods We included patients aged $\geq 60$ years with a diagnosis of non-curable cancer, who have heard the treatment options from their oncologists. In the intervention group, patients consulted their GP using an Outcome Prioritisation Tool (OPT) to discuss the prioritisation of treatment goals (staying alive, maintaining independence, reduce pain, reduce other symptoms). The control group received care as usual. 
Primary outcome was the score on a decision self-efficacy scale after the decision-making consultation with the oncologist.

Results Inclusion ends on 1 January 2019. Results are not yet available but we will present the first results during the conference.

Conclusion The OPTion-study provides information about the effect of a consultation, about preferred treatment goals, between GPs and older patients with non-curable cancer on self-efficacy.

\section{P62 THE DISTRESS THERMOMETER AS A PROGNOSTIC TOOL FOR ONE-YEAR SURVIVAL AMONG PATIENTS WITH LUNG CANCER}

${ }^{1} \mathrm{O}$ Geerse $^{*},{ }^{1} \mathrm{D}$ Brandenbarg, ${ }^{2} \mathrm{H}$ Kerstjens, ${ }^{1 \mathrm{~J}}$ Hoekstra-Weebers, 'S Duijts, ${ }^{1} \mathrm{H}$ Burger, ${ }^{3} \mathrm{G}$ Holtman, ${ }^{1} \mathrm{~A}$ Berendsen, ${ }^{1} \mathrm{~T}$ Hiltermann. 'University Medical Center Groningen, Groningen, Netherlands; ${ }^{2}$ University Medical Centre Groningen, GRONINGEN, Netherlands; ${ }^{3}$ University of Groningen, Faculty of Medical Sciences, Groningen, The Netherlands

\subsection{6/spcare-2019-ACPICONGRESSABS.144}

Introduction Use of patient-reported outcome measures is advocated to support high-quality cancer care. We investigated the added value of the Distress Thermometer (DT) when combined with known predictors to assess one-year survival in patients with lung cancer.

Methods Patients had newly diagnosed or recurrent lung cancer, started systemic treatment, and participated in the intervention arm of a previously published randomised trial. A Cox proportional hazards model was fitted based on five selected known predictors for survival. The DT-score was added to this model and contrasted to models including the EORTC-QLQ-C30 global QoL score or the HADS total score. Model performance was evaluated through improvement in the -2 log likelihood, Harrell's C-statistic, and a risk classification.

Results In total, 110 patients were included in the analysis of whom 97 patients accurately completed the DT. Patients with a DT score ${ }^{35}(\mathrm{~N}=51)$ had a lower QoL, more symptoms of anxiety and depression, and a shorter median survival time (7.6 months vs 10.0 months; $\mathrm{P}=0.02$ ) than patients with a DT score $<5(\mathrm{~N}=46)$. Addition of the DT resulted in a significant improvement in the accuracy of the model to predict one-year survival $(\mathrm{P}<0.001)$ and the discriminatory value $(\mathrm{C}$ statistic) marginally improved from 0.69 to 0.71 . The proportion of patients correctly classified as high risk ( ${ }^{3} 85 \%$ risk of dying within one year) increased from $8 \%$ to $28 \%$.

Conclusions Use of the DT allows clinicians to better identify patients with lung cancer at risk for poor survival, further explore sources of distress, and personalize care accordingly.

\section{P63 RECRUITING PATIENTS IN DIFFICULT ENVIRONMENTS - PRACTICAL EXPERIENCES FROM A GERMAN CACP TRIAL}

J Koch*, C PD Dr Seifart, P Von Blanckenburg. Philipps-University Marburg, MARBURG, Germany

\subsection{6/spcare-2019-ACPICONGRESSABS. 145}

Background Researchers recruiting patients for clinical - nonpharmacological - studies in palliative cancer settings face multiple problems. Patients life expectancy is limited, physical and psychological wellbeing can be volatile and medical treatment tends to be challenging and tiring for patients. Rejection and dropout rates for scientific trials in general are therefore high, especially if concerning advance care planning (ACP).

Aim Recruitment is often assigned to few members of staff who then gain a lot of experience in the matter, formal transition of knowledge can be difficult if

- a.) theoretical framework about recruitment; and

- b.) practical examples how to handle difficult recruitment conversations; are missing.

To address and overcome b.), we have developed "miniinterventions". These aim to change perspective of patients on participation in our randomized controlled ACP trial, and can be applied generally.

Results We developed several interventions covering the following topics:

-Misconceptions towards "psychological" support and academic research

-Physical and emotional wellbeing and therefore no need to partake in the trial

-Time constraints, unwillingness to invest more time in "treatment" than necessary

-Fear of burdening care givers with psychological involvement

With these "mini interventions" delegation of recruitment and training of recruitment staff is eased and the recruitment process and success does not rely solely on single experienced staff members.

Conclusion Interventions in recruitment conversations may have several effects, including improvement of patient decision making, increase of recruitment numbers and better transition of knowledge in research teams.

We seek to cross-link with other international groups facing similar challenges concerning recruiting.

\section{P65 DEVELOPMENT OF A PEDIATRIC ADVANCE CARE PLANNING INTERVENTION}

1J Fahner* ${ }^{2}$ J Rietjens, ${ }^{2} \mathrm{~A}$ van der Heide, ${ }^{1} \mathrm{~J}$ van Delden, ${ }^{1} \mathrm{M}$ Kars. ${ }^{1}$ University Medical Center Utrecht, Utrecht, Netherlands; ${ }^{2}$ Erasmus MC, Rotterdam, Netherlands

\subsection{6/spcare-2019-ACPICONGRESSABS. 146}

Background ACP-conversations in pediatrics seem to occur too late and infrequent. Standards to conduct ACP-conversations are lacking. This study describes the development of an evidence-based pediatric ACP-intervention.

Methods The Medical Research Council framework for development and evaluation of complex interventions was used to structure the developmental process. The process included a systematic review, expert review, a survey among pediatricians and qualitative research among parents, adolescents and health care professionals (HCPs). Behavioral theories and theories of coping with bereavement and loss underpinned the intervention.

Results ACP was seen as an ongoing communicative process, where children and their families work together with HCPs to discover, discuss and document values, preferences and goals of care. The intervention supports ACP by 1) educational materials, 2) an ACP conversation guide and 3) a training for HCPs. Educational materials prepare children and parents by clarifying the concept of ACP and providing preparation 